\title{
MADDOC Regimen
}

National Cancer Institute

\section{Source}

National Cancer Institute. MADDOC Regimen. NCI Thesaurus. Code C9692.

A chemotherapy regimen consisting of mechlorethamine, doxorubicin, cisplatin, dacarbazine, vincristine, and cyclophosphamide that may be used in the treatment of neuroblastoma. 